\title{
O PROCESSO HISTÓRICO DE OCUPAÇÃO DO PARQUE JOÃO PAULO II E AS POLÍTICAS PÚBLICAS ADOTADAS PARA A REDUÇÃO DO RISCO DE DESASTRES
}

\author{
El proceso histórico de ocupación del parque João Paulo II y las políticas públicas \\ adoptadas para la reducción del riesgo de desastres
}

The historic process of occupancy of the park João Paulo II and the public policies adopted for the reduction of the risk of disasters

\section{Le processus historique d'occupation du parc João Paulo II et les politiques publiques adoptées pour la réduction des risques de catastrophes}

Talita Santiago Lopes

Mestra em Defesa e Segurança Civil pela UFF talitalopes18@gmail.com

Daniele Rocha Teixeira

Mestra em Defesa e Segurança Civil pela UFF danieledireito@hotmail.com

Francisco Luiz Guimarães Leitão Discente do PPG em Defesa e Segurança Civil na UFF francisco@exasis.com.br

Gerônimo Emilio Almeida Leitão

Professor do Mestrado em Defesa e Segurança Civil da UFF geronimo_leitao@uol.com.br

Artigo enviado para publicação em 09/04/2019 e aceito em 17/06/2019

DOI: 10.12957/tamoios.2019.41869

\section{Resumo}

Este trabalho pretendeu compreender o processo de urbanização da comunidade João Paulo II e quais as políticas públicas adotadas para a redução do risco de desastres e promoção de uma melhor qualidade de vida para os moradores. A pesquisa se baseou na contextualização histórica da ocupação da favela através de sites que contêm periódicos científicos, reportagens, planos e livros sobre o processo histórico de formação dos bairros e favelas do município do Rio de Janeiro. Sites oficiais do governo foram utilizados para obtenção de dados demográficos e econômicos. Uma pesquisa de campo foi realizada e informações levantadas junto aos moradores e a Defesa Civil municipal. O site GEOPEA foi a base de dados consultada para obtenção dos mapas que delimitam as áreas de risco geológico. A comunidade contou ao longo das últimas décadas com programas de urbanização e habitação implantados, assim como algumas obras de contenção de encostas e projetos de cunho socioambiental. A participação da própria comunidade no processo deve ser priorizada para dar legitimidade às ações, garantir a eficácia e evitar o estabelecimento de novos conflitos. Um adequado planejamento das áreas suscetíveis a desastres é necessário para que o risco seja mitigado, na medida do possível.

Palavras Chave: Comunidades; Favelas; Risco; Desastres.

\section{Resumen}

Este trabajo pretendió comprender el proceso de urbanización de la comunidad João Paulo II y cuáles las políticas públicas adoptadas para la reducción del riesgo de desastres y promoción de 
una mejor calidad de vida para los habitantes. La investigación se basó en la contextualización histórica de la ocupación de la favela a través de sitios que contienen periódicos científicos, reportajes, planes y libros sobre el proceso histórico de formación de los barrios y favelas del municipio de Rio de Janeiro. Los sitios oficiales del gobierno se utilizaron para obtener datos demográficos y económicos. Una encuesta de campo fue realizada e informaciones levantadas junto a los residentes y la Defensa Civil municipal. El sitio GEOPEA fue la base de datos consultada para obtener los mapas que delimitan las áreas de riesgo geológico. La comunidad ha contado a lo largo de las últimas décadas con programas de urbanización y vivienda implantados, así como algunas obras de contención de laderas y proyectos de carácter socioambiental. La participación de la propia comunidad en el proceso debe ser priorizada para dar legitimidad a las acciones, garantizar la eficacia y evitar el establecimiento de nuevos conflictos. Una adecuada planificación de las áreas susceptibles a desastres es necesaria, para que el riesgo sea mitigado en la medida de lo posible.

Palabras clave: Comunidades; Favelas; Riesgo; Desastres.

\begin{abstract}
This paper aimed to understand the process of urbanization of the João Paulo II community and what public policies were adopted to reduce disaster risk and promote a better quality of life for residents. The research was based on historical contextualization of the occupation of the favela through sites containing scientific journals, reports, plans and books on the historical process of formation of the districts and favelas of the city of Rio de Janeiro. Official government websites were used to obtain demographic and economic data. A field survey was conducted and information was collected from the residents and the Municipal Civil Defense. The GEOPEA site was the database consulted to obtain the maps that delimit the areas of geological risk. Over the last decades, the community has had urbanization and housing programs in place, as well as some slope containment and socio-environmental projects. The participation of the community itself in the process must be prioritized to give legitimacy to actions, ensure effectiveness and prevent the establishment of new conflicts. Adequate planning of areas susceptible to disasters is necessary so that the risk is mitigated as much as possible.
\end{abstract}

Keywords: Communities; Shanty towns; Risk; Disasters.

\title{
Résumé
}

Ce document visait à comprendre le processus d'urbanisation de la communauté Jean-Paul II et les politiques publiques adoptées pour réduire les risques de catastrophe et promouvoir une meilleure qualité de vie des résidents. La recherche était basée sur la contextualisation historique de l'occupation de la favela à travers des sites contenant des revues scientifiques, des rapports, des plans et des livres sur le processus historique de formation des districts et des favelas de la ville de Rio de Janeiro. Les sites Web officiels du gouvernement ont été utilisés pour obtenir des données démographiques et économiques. Une enquête sur le terrain a été réalisée et des informations ont été recueillies auprès des résidents et de la Défense civile municipale. Le site GEOPEA a été la base de données consultée pour obtenir les cartes délimitant les zones à risque géologique. Au cours des dernières décennies, la communauté a mis en place des programmes d'urbanisation et de logement, ainsi que des projets de limitation des pentes et socioenvironnementaux. La participation de la communauté elle-même au processus doit être priorisée pour donner une légitimité aux actions, assurer l'efficacité et empêcher la création de nouveaux conflits. Une planification adéquate des zones exposées aux catastrophes est nécessaire pour que le risque soit atténué autant que possible.

Mots-clés: Communautés; Taudis; Risque; Les catastrophes. 


\section{Introdução}

Um dos princípios fundamentais consagrados pela Constituição Federal de 1988 é o da dignidade da pessoa humana e para assegurar a dignidade ao cidadão, o artigo $6^{\circ}$ em seu caput, determina que a moradia é um direito social (BRASIL, 1988). Contrapõese a esse direito fundamental a dificuldade que muitos brasileiros têm em adquirir seu imóvel próprio e a ausência de áreas adequadas para a construção de moradias em algumas partes do país.

No estado do Rio de Janeiro, por exemplo, há predomínio de áreas declivosas e, em sua maioria, inadequadas para a construção de moradias por apresentarem alta probabilidade de movimentação de massa, um fenômeno natural típico da dinâmica de encostas.

O estudo de Schlee (2013) destaca que a ocupação urbana nas encostas se iniciou no fundo dos vales: "As cidades litorâneas (Rio de Janeiro, Florianópolis e Vitória), onde as vertentes são mais íngremes e as declividades são mais expressivas, os percursos ao longo dos talvegues e fundos de vale foram os pioneiros e ainda predominam". A partir destas primeiras ocupações, as ocupações irregulares na cidade do Rio de Janeiro passaram para as encostas, áreas de instabilidade geológica, que combinadas a interferência antrópica, configuram-se como áreas de risco. Há que considerar, ainda, nesse quadro de ocupação informal do solo urbano, o fato de que os chamados "assentamentos espontâneos" se localizam em áreas onde há restrições legais para a ação dos empreendedores imobiliários, como áreas de declividade acentuada e margens de rios e lagoas, por exemplo.

A inexistência, ao longo de décadas, de políticas habitacionais voltadas para o atendimento da parcela mais pobre da população brasileira, bem como o reconhecimento da favela como parte integrante da cidade, contribuíram para a expansão da informalidade urbana, embora seja necessário reconhecer que, na cidade do Rio de Janeiro a partir de 1995, foram implementadas políticas de regularização urbanística desses assentamentos, o que contribuiu para a melhoria da qualidade de vida da população local e das condições de segurança no que se refere à ocupação do solo.

A relação do Estado com as Comunidades Faveladas passou por diferentes fases ao longo dos últimos cem anos. Negação, confronto, tolerância e, por último, aceitação ainda que com restrições de alguns setores da sociedade - parecem expressar as diferentes etapas dessa relação. A favela também se transformou, e muito, durante esse período, dos "assentamentos provisórios" de migrantes aos "bairros populares", onde famílias já vivem há algumas gerações (LEITÃO, 2009).

"Os deslizamentos de encostas têm aumentado consideravelmente nas últimas décadas, principalmente nos centros urbanos dos países denominados emergentes, onde esses movimentos gravitacionais de massa são agravados em função da urbanização intensa e da construção de residências em encostas acentuadas" (CORTEZ \& FILHO, 2010). Entende-se que o crescimento do número de domicílios e assentamentos informais em áreas de encosta no município do Rio de Janeiro ocorreu devido à oferta de empregos e das políticas públicas de ocupação e uso do solo desenvolvidas nas últimas décadas. Essas moradias foram construídas sem planejamento, em terrenos topograficamente inclinados e instáveis, suscetíveis a movimentos de massa e enxurradas. 


\section{Objetivo}

Compreender como se deu o processo de urbanização da comunidade João Paulo II, situada na encosta do Complexo Andaraí e Grajaú, e quais as políticas públicas desenvolvidas para promover a redução de riscos de desastres e melhorar a qualidade de vida para a população residente.

\section{Metodologia}

A pesquisa se baseou na contextualização histórica da ocupação da comunidade João Paulo II através da busca por publicações em sites da Internet que contêm coleções de periódicos científicos como Scielo, Google Acadêmico e Periódicos CAPES, assim como reportagens, planos e livros que tratavam sobre o processo histórico de formação dos bairros e favelas do município do Rio de Janeiro. Um levantamento de campo foi realizado na comunidade e entrevistas foram realizadas com a líder comunitária e alguns moradores. Sites oficiais do Governo foram utilizados para obtenção dos dados demográficos e econômicos. Informações sobre ações voltadas para a promoção da segurança dos moradores e redução do risco de desastres foram levantadas junto a Defesa Civil municipal. O site GEOPEA, de domínio da Prefeitura do Rio de Janeiro, foi a base de dados consultada para obtenção dos mapas que delimitam a área total da comunidade e as áreas de baixo, médio e alto risco geológico.

\section{A área de estudo: o Complexo do Andaraí e Grajaú}

O Complexo do Andaraí e Grajaú compreende seis comunidades, segundo a divisão geoespacial adotada pela Prefeitura do Rio de Janeiro. Localizadas nos bairros que possuem o mesmo nome do complexo, as comunidades são denominadas de Morro do Andaraí, Jamelão, Juscelino Kubitschek chamado também de Caçapava, João Paulo II (ou Sá Viana), Nova Divinéia e Vila Rica (ou Borda do Mato). O povoamento das encostas no entorno do bairro do Andaraí e Grajaú datam do início dos primeiros anos do século XX, com a formação da comunidade Arrelia (atualmente é considerada uma subdivisão do Morro do Andaraí), acredita-se que tenha sido a primeira favela a existir na Zona Norte do Rio de Janeiro (GOVERNO DO RIO DE JANEIRO, 2013).

No fim do século XIX, com a decadência da cultura cafeeira, as fazendas que ocupavam o Andaraí começaram a ser divididas alterando o perfil do bairro que passou a ser ocupado por fábricas, tornando-se um bairro operário. Iniciou-se então a construção de vilas operárias como alternativa de moradia para os trabalhadores atraídos para a região. No entanto, muitos desses operários não encontravam moradia nessas vilas e/ou não tinham condição financeira de pagar o valor dos aluguéis cobrados no bairro. Desta forma, como alternativa para a construção de suas casas próximo ao local de trabalho, começaram a ocupar as áreas de encosta da região (BARROS, COUTINHO \& RIBEIRO, 2006). Esse processo histórico é um exemplo do tipo de desenvolvimento urbano pelo qual o Rio de Janeiro passou, que elitizou os espaços urbanos centrais e culminou na periferização das classes de baixa renda (LEITE, 2001). Como se sabe, uma das consequências desta política que incluía a remoção de cortiços e de moradias precárias nos morros da área central da cidade, levou a ocupação das áreas de encostas, públicas e privadas, em regiões onde houvesse oferta de empregos industriais, no comércio e/ou domésticos (LEITE, 2001).

O processo de favelização do bairro do Grajaú é mais recente e, embora o Censo de Favelas de 1948 registrasse a existência da favela da Caixa d'Água ou Vila Rica na 
Rua Borda do Mato com 20 domicílios, a maior parte das favelas do bairro surgiu a partir dos anos 70. Campo Grande se formou em 1976, Nova Divinéia em 1971, João Paulo II em 1979 e Juscelino Kubitschek nos anos 80. O vale em que se situa o bairro é circundado por encostas, que hoje são ocupadas por diversas favelas, dispostas em uma espécie de ferradura em torno da área urbanizada central (LEITE, 2001).

Segundo Franca, Leite e Santos (2003), as favelas atualmente nas encostas podem ser entendidas como decorrência de três motivos que se sucederam a partir de meados do século XIX: controle rigoroso das condições de higiene das habitações coletivas pela autoridade municipal, o fracasso de uma aliança entre o governo e os empresários do setor imobiliário e financeiro ao incentivar a construção de vilas operárias e a regularização extrema da forma de habitação popular que caracterizou a Reforma Passos de 1902 a 1906. As encostas se apresentaram como alternativa para a população de baixa renda, onde é possível construir livremente, sem as imposições do governo, e utilizar a natureza para prestar os serviços ambientais e extrair recursos naturais, ao invés de pagar por eles (FRANCA, LEITE \& SANTOS, 2003).

O solo com valor de uso elevado não pode ser espaço ocupado por favela, mas sim por algo mais nobre. Com isso associou-se às favelas o significado de risco. Durante o século $\mathrm{XX}$, foram inúmeros desastres ocasionados por chuvas intensas com perda de vidas e patrimônio. A favela é um espaço associado a um significado hídrico, pois sempre exigiu de quem mora ali uma rotina diária de obtenção de água e descarte de esgoto. A falta de políticas públicas e de planejamento a longo prazo favoreceu o surgimento de novas comunidades e o crescimento das já existentes, que continuam a se multiplicar, apesar de muitas terem sido removidas. O verde dos morros foi sendo substituído por brasileiros de todas as regiões (FRANCA, LEITE \& SANTOS, 2003).

A partir da década de 1980 a Prefeitura do Rio de Janeiro começou a acompanhar as ocupações irregulares da cidade através do cadastramento desses assentamentos. As primeiras delimitações das favelas cariocas, produzidas para o Cadastro de Favelas, foram realizadas sobre as plantas cadastrais de 1975, na escala de 1:2.000, a partir de voo aerofotogramétrico associado à pesquisa de campo, que gerou como produto final mapas individualizados das favelas. Em 1997 e 2000 novos voos foram feitos e resultaram nos atuais registros digitais da cidade. Mantendo o objetivo da atualização cadastral e de monitoramento da evolução urbana, foi elaborada uma nova coleção de ortofotos de toda a cidade em 2004, desta vez a partir de um voo aerofotogramétrico na altura de 15.000 metros que produziu fotografias na escala de 1:10.000 (CAVALLIERI \& LOPES, 2006). Este tipo de mapeamento auxilia no monitoramento e na delimitação da expansão dessas áreas, sendo um importante instrumento auxiliar para tomada de decisão e implantação de políticas urbanísticas.

Estas áreas ocupadas irregularmente dão origem às favelas ou comunidades carentes. São denominadas pelo Instituto Brasileiro de Geografia e Estatística (IBGE) de aglomerados subnormais e caracterizadas como um conjunto constituído por 51 ou mais unidades habitacionais sem título de propriedade, e por, pelo menos, uma das seguintes características: irregularidade das vias de circulação e do tamanho e forma dos lotes e/ou carência de serviços públicos essenciais (como coleta de lixo, rede de esgoto, rede de água, energia elétrica e iluminação pública). O surgimento desses aglomerados subnormais se relaciona à forte especulação imobiliária e fundiária, ao decorrente espraiamento territorial do tecido urbano e à carência de infraestruturas. Desenvolvem-se como uma resposta de uma parcela da população à necessidade de moradia que vai habitar espaços menos valorizados pelo setor imobiliário e fundiário (IBGE, 2010).

A comunidade estudada, o Parque João Paulo II, de acordo com a delimitação da Prefeitura do Rio de Janeiro, pertence à Região Administrativa de Vila Isabel (IX RA). O 
Censo do IBGE em 2010 identificou a quantidade de domicílios particulares ocupados em aglomerados subnormais e a população residente em todas as favelas do país. No Parque João Paulo II existia, até o levantamento, 811 domicílios e uma população de 2.616 habitantes, sendo 1.252 homens e 1.364 mulheres. A área ocupada em 2008 correspondia a 76.659,49 $\mathrm{m}^{2}$ (CAVALLIERI \& VIAL, 2009). O Portal GEORIO, de domínio da Prefeitura do Rio de Janeiro, disponibiliza gratuitamente imagens de satélite e mapas digitais das comunidades cariocas com demarcações dos limites (Figura 1).

Figura 1. Área total da comunidade Parque João Paulo II.

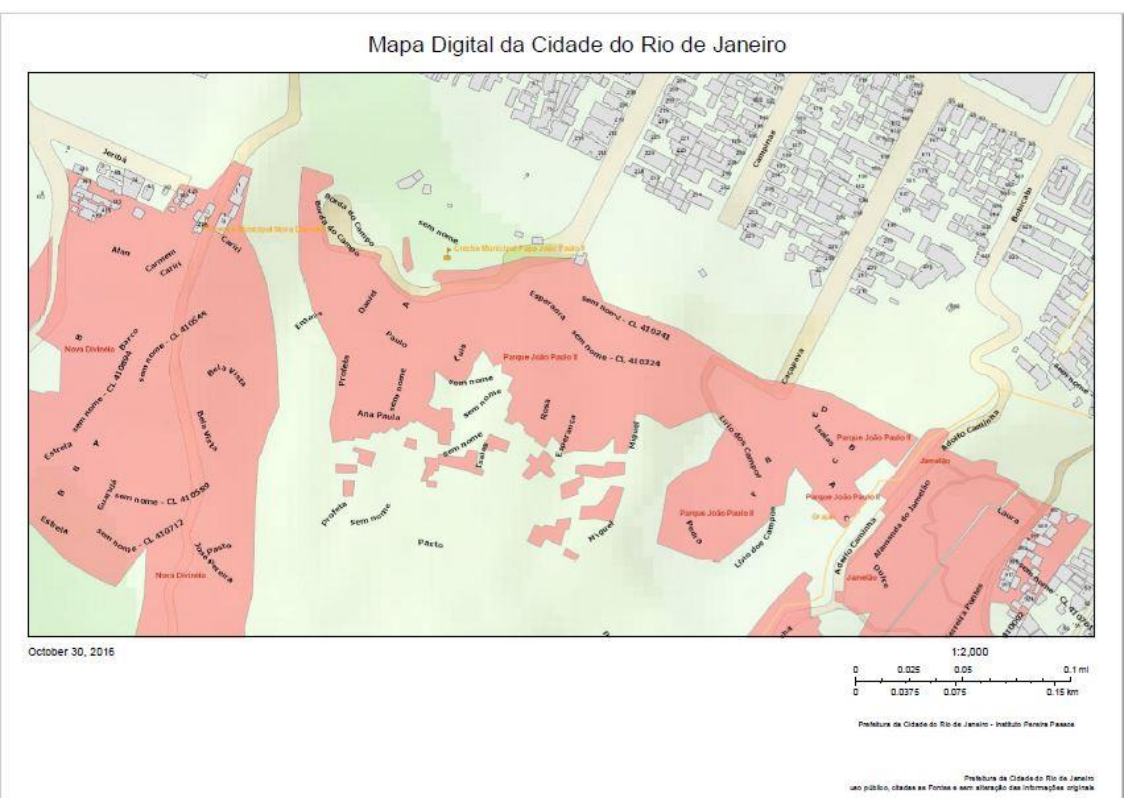

Fonte: GEORIO, 2016

\section{Resultados e discussão}

\section{A comunidade João Paulo II e as políticas públicas de urbanização}

Com a crescente expansão dos aglomerados subnormais, a precariedade estrutural presente nos mesmos, a consequente baixa qualidade de vida e o risco a que a população residente está sujeita, políticas públicas para melhoria das favelas começaram a ser projetadas e implantadas. Segundo Delecave \& Leitão (2014), desde a década de 80, com o projeto amostral de intervenção urbanística nas Favelas Pavão-Pavãozinho e Cantagalo, o governo pretendia transformar as favelas em bairros populares. O projeto desenvolvido entre 1984 e 1986 almejava contemplar 12 mil pessoas com obras de infraestrutura, acessibilidade e transporte, além de unidades habitacionais para as famílias que ficassem desalojadas pelas obras de urbanização. De acordo com os autores, somente com o Plano Diretor da Cidade do Rio de Janeiro de 1992, as favelas ganharam uma maior expressão com a criação do Programa Favela Bairro, em 1994. O projeto objetivava implementar obras de infraestrutura urbana, acessibilidade e criação de equipamentos urbanos, promovendo a transformação da favela em bairro.

No total, foram 143 favelas beneficiadas pelo programa Favela Bairro em 14 anos, atendendo um conjunto de 556.000 moradores. Paralelamente a este programa, desenvolveram-se outros, como o Bairrinho (44 comunidades e 62.000 moradores atendidos) e o Grandes Favelas com 4 comunidades e 163.316 moradores atendidos 
(PINHEIRO, 2008). A comunidade Parque João Paulo II foi uma das favelas contempladas pelo Favela Bairro (Figura 2).

Figura 2. Representação gráfica do Projeto Favela Bairro para as comunidades Parque João Paulo II, Nova Divinéia, Borda do Mato e Parque JK (2001).

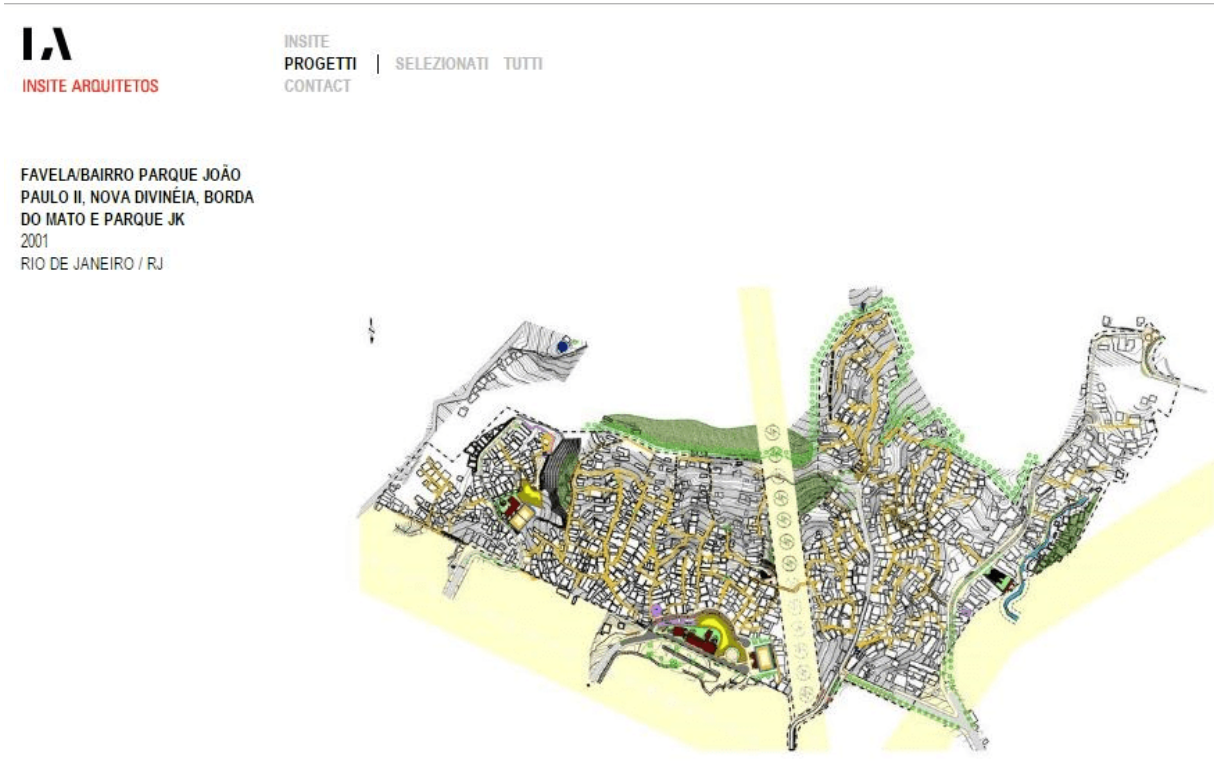

Fonte: INSITE ARQUITETOS, 2001

Outros programas governamentais desenvolvidos na comunidade foram o Minha Casa, Minha Vida do Governo Federal, e o mais recente programa habitacional da Prefeitura da Cidade do Rio de Janeiro, o Morar Carioca. Este último, "lançado em julho de 2010 pela Secretaria Municipal de Habitação, tem por objetivo urbanizar todas as favelas até 2020, incorporando conceitos de sustentabilidade, moradia e acessibilidade, contando com 8 milhões de orçamento" (DELECAVE \& LEITÃO, 2014). No site do Programa de Aceleração do Crescimento do Governo Federal (PAC), o investimento declarado entre os anos de 2007 e 2010 para as comunidades Parque João Paulo II, Nova Divinéia, Borda do Mato e Parque JK foi de R\$ 18.261.974,80.

\section{As obras realizadas na comunidade e o investimento em Defesa e Segurança Civil}

Por ter se expandido ao longo de uma encosta declivosa, a comunidade Parque João Paulo II possui muitas áreas de risco geológico. Apesar de ser uma comunidade pequena, a maior parte da área está delimitada como alta suscetibilidade a risco de escorregamentos de acordo os mapas digitais disponíveis para consulta no site GEORIO (Figura 3).

A demarcação feita em vermelho claro mostra a área total da comunidade, a cor vermelha escura identifica as áreas com maior risco de escorregamento, o restante do mapa em amarelo caracteriza a área com médio risco. Nenhuma parte da área mapeada é classificada como baixo risco (representada pela cor verde). 
Figura 3. Mapa digital de suscetibilidade a escorregamento do Parque João Paulo II.

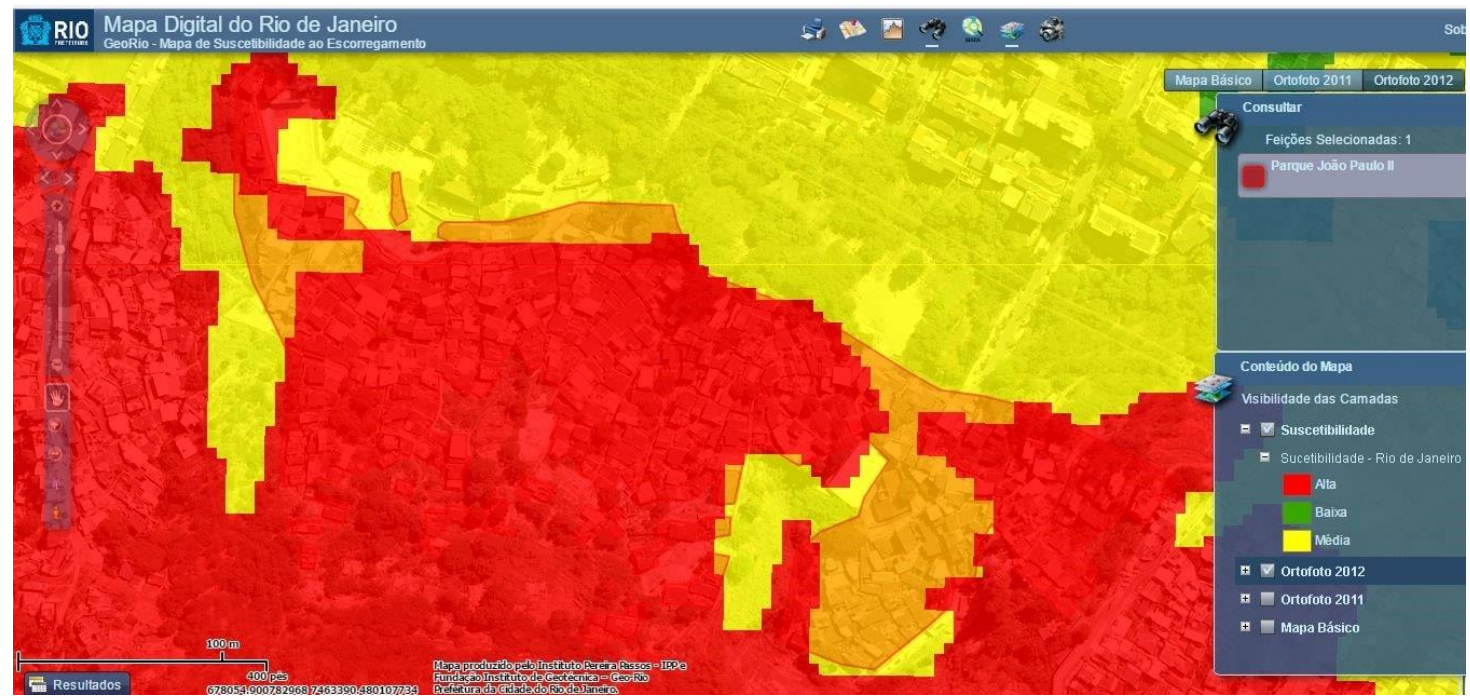

Fonte: GEORIO, 2016.

Em visita de campo à comunidade, realizada em 30 de setembro de 2016, a Presidente da Associação de Moradores, incumbida do papel de líder comunitária, se propôs a conceder uma entrevista e mostrar as áreas mais críticas segundo seu ponto de vista. Outros moradores que optaram por não se identificar, falaram sobre as melhorias realizadas e os problemas que ainda persistem conforme a percepção deles.

Sobre o Programa Minha Casa, Minha Vida relataram que em 2010 houve a necessidade de destinar essas moradias às famílias que tiveram suas casas afetadas por chuvas intensas. O programa atendeu aproximadamente 120 famílias, mas ainda resta um pequeno número de famílias, que não souberam mensurar exatamente, esperando para serem reassentadas. As famílias foram encaminhadas para o conjunto habitacional nos bairros Senador Câmara, Triagem (Bairro Carioca) e Santa Cruz. No entanto, algumas famílias não aceitaram ir para Santa Cruz e Senador Câmara e preferiram esperar para irem morar no Bairro Carioca. A líder comunitária relatou que a habitação é fornecida gratuitamente, os moradores pagam somente os encargos referentes a prestação de serviços como luz, gás e condomínio. Segundo ela, o motivo apontado por alguns moradores para se recusarem a morar em Santa Cruz e Senador Câmara é que, além de serem longe de seus respectivos trabalhos, são áreas conflituosas. O Parque João Paulo II é uma comunidade dominada por um comando rival, assim moradores que foram para as casas em Santa Cruz e Senador Câmara foram impedidos de ocupar os imóveis e obrigados a retornar ao Parque João Paulo II. A reclamação recorrente dos moradores que aguardam novas casas é que, embora não haja mais unidades no Bairro Carioca onde a maioria espera vaga por não ter influência de grupos dominantes, há a cobrança de um pagamento mensal de um "valor simbólico" para entregarem a casa. Para eles é inviável financeiramente o pagamento da taxa cobrada.

A líder comunitária relatou que na comunidade João Paulo II nem todas as casas possuem rede de esgoto e água tratada. As frequentes chuvas e consequentes deslizamentos danificaram a melhor rede de esgotamento sanitário construída na comunidade. A manutenção das redes de esgoto é feita pela Associação dos Moradores dentro do possível. Na entrada da comunidade tem uma bomba de captação d'água que atende parte da demanda. Existe uma ligação que vem da caixa d'água da comunidade Divinéia, atendendo a parte alta do Parque João Paulo II, e uma outra bomba que vem da 
comunidade Borda do Mato, atendendo algumas casas que se situam ao final da Rua Sá Vianna. Segundo eles, está em estudo na Companhia Estadual de Águas e Esgotos do Rio de Janeiro (CEDAE) a construção de uma caixa de água única que atenderá toda a parte mais alta da comunidade.

Outro problema apontado é a drenagem das águas pluviais. As canaletas construídas não são suficientes para o escoamento e não há limpeza, ficando cheias de galhos, folhas e resíduos sólidos. Estes materiais obstruem a passagem da água e dificultam o escoamento, causando o transbordo (Figura 4). Com a retirada dos projetos Guardião do Rio e Gari Comunitário ficou difícil manter as canaletas desobstruídas segundo relatos de moradores.

Figura 4. Canaleta com folhas, galhos e resíduos sólidos.

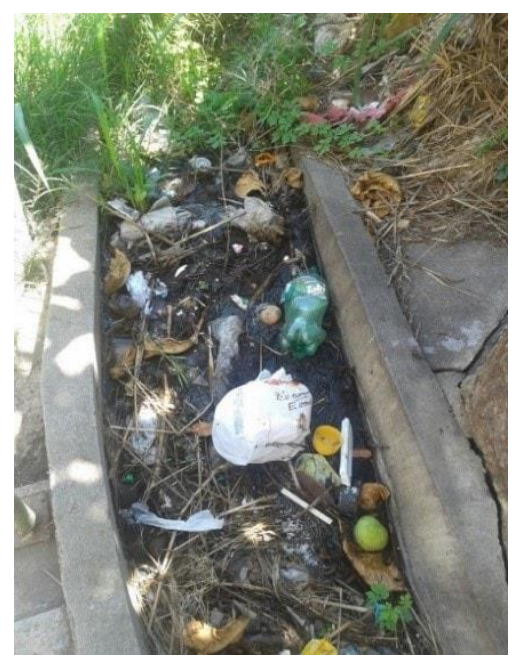

Fonte: AUTOR, 2016.

O Programa Guardião do Rio foi criado para auxiliar na limpeza dos rios cariocas, recolher resíduos urbanos dentro de rios e córregos, promover a conscientização ambiental das comunidades envolvidas e revegetar as margens. Integraram o Programa: a Companhia Municipal de Limpeza Urbana (COMLURB), a Fundação Rio-Águas e as Secretarias Municipais de Meio Ambiente, Saúde, Educação, Assistência Social e Defesa Civil. Foi implantado em 24 trechos de rios em 23 comunidades (BRASIL, 2016). O Projeto Gari Comunitário surgiu da necessidade de criação de alternativas para uma melhor conservação e limpeza dos bairros da cidade. Tinha como filosofia o envolvimento das comunidades na execução dos serviços de limpeza urbana como varrição de becos e ruas, limpeza de escadarias, canaletas, de ralos e sarjetas, limpeza de encostas, roçada, capina, pintura de meio fio e lavação de ruas. O projeto teve fim em 2010 (BRASIL, 2016).

Sobre o novo programa de governo do Município do Rio de Janeiro, O Morar Carioca, a líder comunitária considera ter promovido uma mudança positiva na comunidade. Havia um local crítico onde faltava água, o esgoto era lançado a céu aberto, lixo jogado na rua e com alta proliferação de roedores. As famílias que residiam no local foram removidas e reassentadas, no lugar das casas construíram um centro esportivo e uma pracinha para recreação (Figura 5). 
Figura 5. Pracinha (à esquerda) e quadra de esportes (à direita) construídos pelo Programa Morar Carioca.

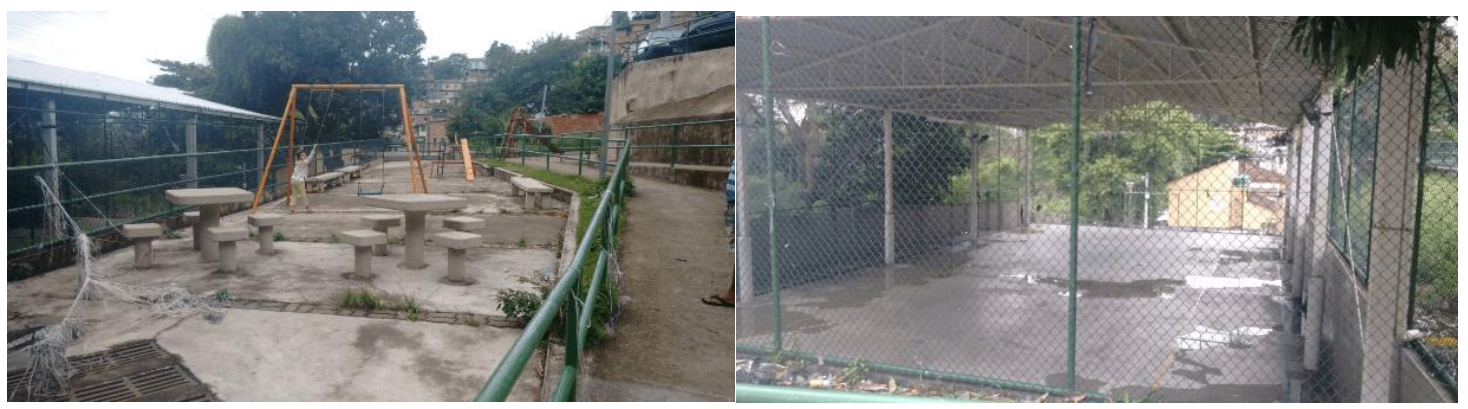

Fonte: AUTOR, 2016.

O Programa também construiu um muro de contenção no local chamado de "caminho do pasto", onde ocorreu um deslizamento em 1982 e atingiu a Travessa Profeta Daniel. Este é considerado o maior desastre que se tem conhecimento na comunidade. Uma rocha de grande dimensão se deslocou e atingiu 6 casas, levando 14 pessoas a óbito. A rocha mobilizada não foi removida do local e construíram uma cruz em memória das vítimas (Figura 6).

Figura 6. Rocha que deslizou sobre 6 casas em 1982 e vitimou 14 pessoas.

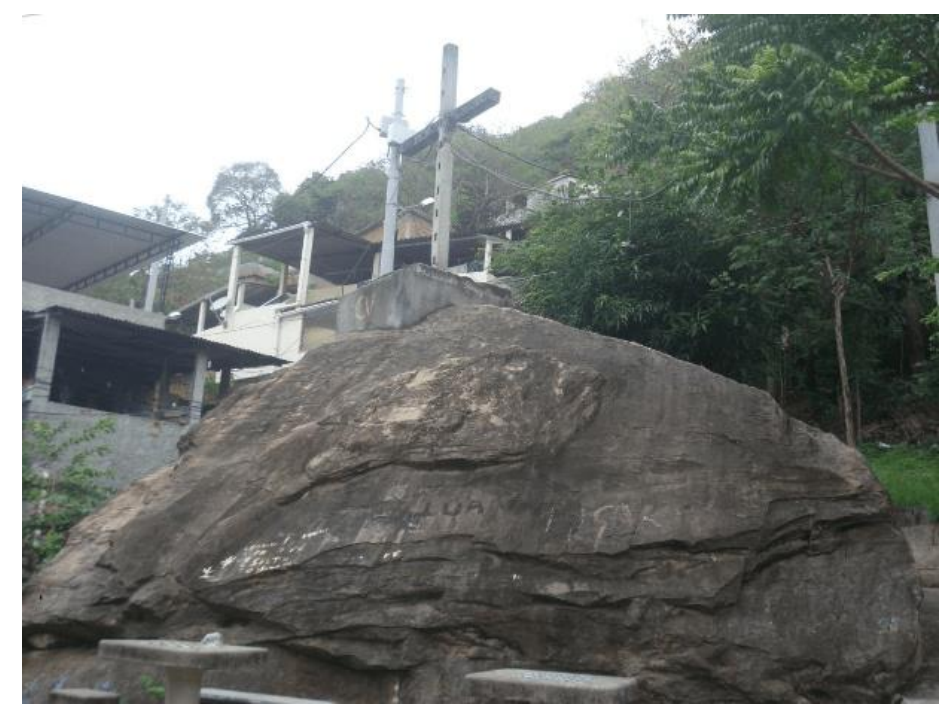

Fonte: AUTOR, 2016

A líder comunitária e alguns moradores disseram considerar a Defesa Civil Municipal atuante e atenciosa com a comunidade. Afirmam ser o primeiro órgão a chegar ao local sempre que solicitado e atende prontamente. Faz o acompanhamento das sirenes instaladas na Creche Municipal Papa João Paulo II, construída dentro da comunidade (Figura 7), e periodicamente desenvolve simulados instrutivos com os moradores para que saibam como agir em situações de desastre ou de alerta. Quando ocorrem chuvas com potencial para saturação do solo e deflagração de movimentos de massa, o Centro de Operações da Defesa Civil avisa as lideranças comunitárias, que por sua vez, repassam as informações aos moradores, para que eles se dirijam aos pontos de apoio préestipulados. São oferecidos cursos para alguns moradores e equipamentos como botas, 
lanternas e capas para que, em situações críticas, voluntários da comunidade estejam aptos a auxiliar nas ações da Defesa Civil.

Figura 7. Creche (à esquerda) e as sirenes para alerta da população (à direita).

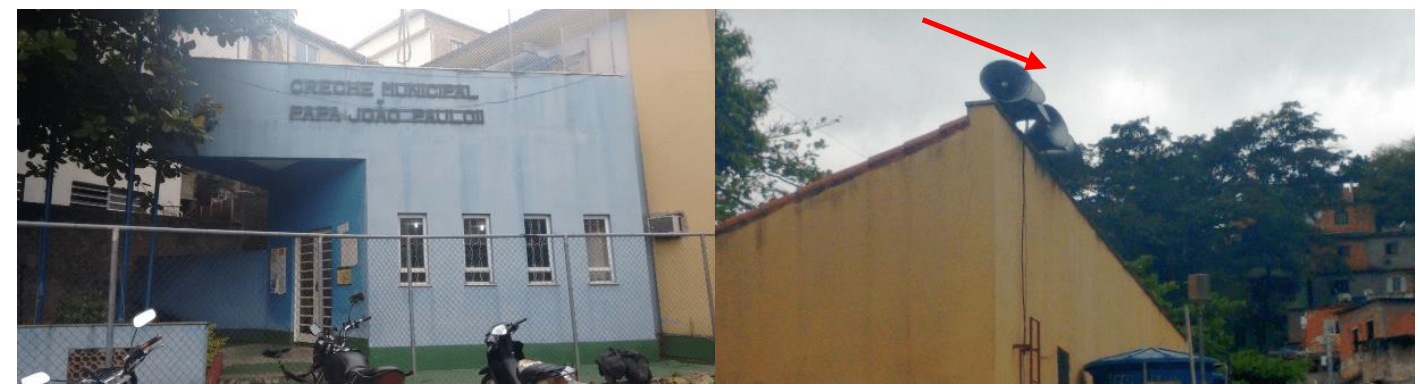

Fonte: AUTOR, 2016.

Os pontos de apoio em situações de alerta ou de desastre são a Associação dos Moradores e as Igrejas Assembleia de Deus e Batista. Segundo informações obtidas junto a Defesa Civil Municipal, não há periodicidade exata para a realização dos simulados. Não está implantado nas escolas do Parque João Paulo II o Projeto Defesa Civil nas escolas, que visa orientar e instruir crianças e adolescentes a protegerem a si mesmos e saberem como agir na iminência de desastres.

Outro problema citado pelos moradores são as enxurradas corriqueiras que atingem muitas casas na comunidade, impossibilitando os moradores de saírem ou entrarem em suas residências. Há alguns anos, uma enxurrada causou a morte de uma moradora, que foi arrastada pela força da água. Os resíduos sólidos dispostos em locais impróprios, que foram vistos em vários pontos, é um agravante da situação de risco natural em função do perfil topográfico da área. Há muitos rejeitos, materiais recicláveis e entulhos jogados nas encostas e canais de drenagem (Figura 8). É notável a falta de conscientização dos moradores, embora haja um trabalho realizado na comunidade através de sistema de som, instruindo os moradores a não jogarem "lixo" nas encostas e canaletas. Este hábito, além de agravar o risco de deslizamentos e outros tipos de movimento de massa por bloquearem o caminho natural das águas, contamina o solo, atrai roedores e insetos, tornando o ambiente extremamente insalubre para quem ali vive.

Figura 8. Descarte indevido de resíduos sólidos e eletrodomésticos nas encostas.

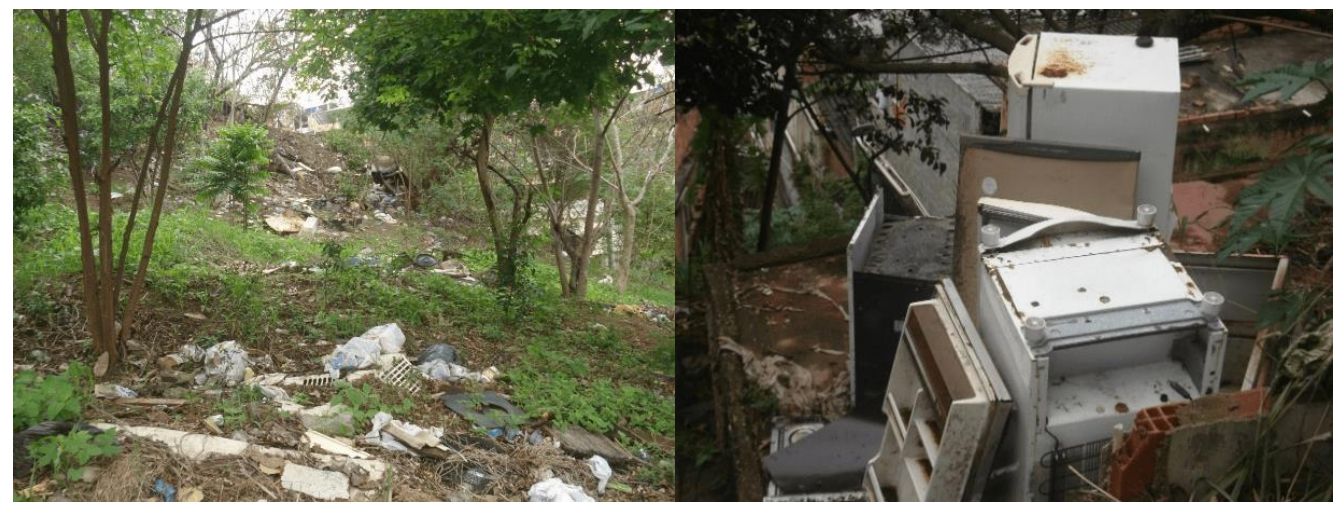

Fonte: AUTOR, 2016.

A Comunidade possuía um projeto chamado Real Reciclar que retirou 14 toneladas de entulho do meio ambiente. Três caçambas doadas à comunidade serviam 
para fazer a reciclagem, no entanto, não havia espaço para a acomodação das mesmas e foram deixadas em um terreno da empresa Light Serviços de Eletricidade, onde havia espaço suficiente. Logo que a empresa tomou conhecimento da ação, mandou murar o terreno e não se mostrou interessada em uma parceria com a comunidade para dar continuidade ao projeto. O auxílio da Prefeitura foi solicitado pela Associação de Moradores, mas não obtiveram resposta afirmativa. Tais empecilhos tornaram inviável para os moradores darem prosseguimento ao projeto de sua iniciativa.

Poucas foram as obras de contenção realizadas pelos projetos implantados na comunidade ao que se pode perceber. Foi feito apenas o capeamento de algumas áreas declivosas e construídos canais de drenagem, na tentativa de evitar movimentos de massa e enxurradas (Figura 9).

Figura 9. Capeamento de encosta realizado no Parque João Paulo II.

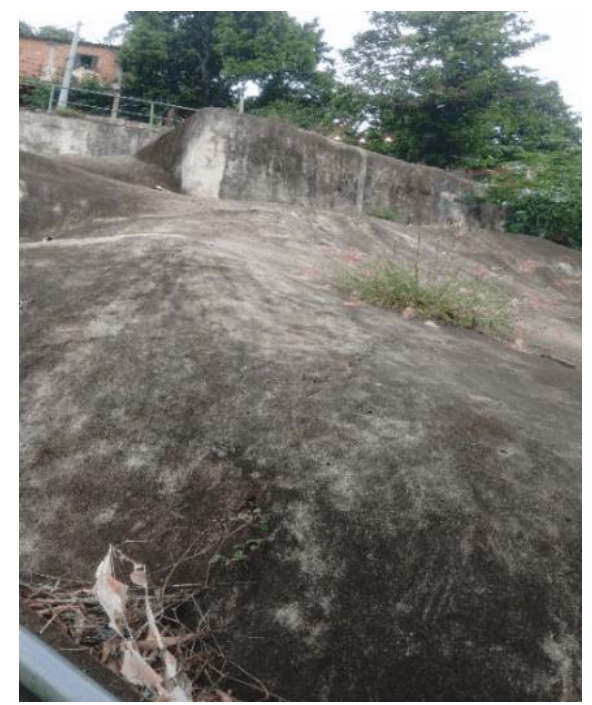

Fonte: AUTOR, 2016

Em 2004, o Programa Favela Bairro contemplou a comunidade com uma obra de contenção na Travessa Luiz, que também era uma área sujeita a deslizamento. Nenhuma outra obra foi vista durante o trabalho de campo.

\section{Principais riscos identificados no Parque João Paulo II}

Segundo o glossário da EIRD - Estratégia Internacional para Redução de Desastres (EIRD/ONU, 2004) o desastre é definido como:

Uma séria interrupção no funcionamento de uma comunidade ou sociedade que ocasiona perdas humanas e/ou importantes perdas materiais, econômicas e ambientais; que excedem a capacidade de uma comunidade ou a sociedade afetada de fazer frente à situação mediante o uso de seus próprios recursos. Um desastre é uma função do processo de risco. Resulta da combinação das ameaças, vulnerabilidade e insuficiente capacidade de reduzir as consequências negativas e potenciais do risco (tradução nossa).

Também podemos encontrar no mesmo glossário a definição de risco:

Probabilidade de consequências prejudiciais ou perdas inesperadas [...] resultado de interações entre ameaças naturais ou antropogênicas e condições 
de vulnerabilidade. Convencionalmente o risco é definido pela expressão Risco = Ameaças x Vulnerabilidades [...] (tradução nossa)

Assim como a definição de ameaça:

Evento físico, potencialmente prejudicial, fenômeno e/ou atividade humana que pode causar a morte ou lesões, danos materiais, interrupção da atividade social e econômica ou degradação ambiental. Incluem condições latentes que podem derivar em futuras ameaças [...] (tradução nossa)

E a definição de vulnerabilidade:

Condições determinadas por fatores ou processos físicos, sociais, econômicos e ambientais, que aumentam a suscetibilidade de uma comunidade ao impacto de ameaças [...] (tradução nossa).

Os pontos importantes nestas definições são que o desastre é uma função do risco, que por sua vez pode ser definido pela interação entre ameaça e vulnerabilidade, sendo que a ameaça é um evento potencialmente prejudicial e a vulnerabilidade é a suscetibilidade ao impacto da ameaça.

Assim, para identificarmos os riscos associados à comunidade, optamos por elencar suas principais ameaças e vulnerabilidades baseada na Classificação e Codificação Brasileira de Desastres (COBRADE), disponibilizada no site do Ministério da Integração.

1. Ameaça de deslizamento e movimento de massa (COBRADE 1.1.3.2.1, 1.1.3.3.1 e 1.1.3.3.2): por estar localizada em uma área declivosa, a comunidade está suscetível a movimentos de massa.

2. Ameaça de enxurrada e alagamento (COBRADE 1.2.2.0.0 e 1.2.3.0.0): embora haja alguns canais de drenagem, estes são insuficientes e os existentes têm manutenção precária e são obstruídos por resíduos sólidos, galhos e folhas;

3. Ameaça de chuvas intensas (COBRADE 1.3.2.1.4): a cidade do Rio de Janeiro tem um histórico de inundações e deslizamentos causados por chuvas intensas. Segundo o Anuário Brasileiro de Desastres Naturais de 2012, 19\% dos movimentos de massa ocorreram no Rio de Janeiro e o motivo principal é a ocorrência frequente de chuvas intensas na região, junto com assentamentos humanos em pequenas bacias urbanizadas (CENAD, 2012);

4. Ameaça de epidemia (COBRADE 1.5.1.1.0): o descarte incorreto dos resíduos sólidos propricia o acumulo da água das chuvas e atrai vetores, como roedores ou mosquitos. Potencializa o risco de epidemias sazonais, como a dengue, chicungunha e zika, transmitidos pelo mosquito Aedes Aegypti, por exemplo. 
Quanto as vulnerabilidades identificadas, destacamos:

1. Econômica: a maioria das famílias são baixa renda e não tem como assumir os custos de morar em áreas com menor risco ou obter financiamento para custear melhorias estruturais;

2. Educacional: a baixa escolaridade influencia na compreensão do risco que determinados comportamentos pode significar para eles mesmos, como acumular "lixo" nas encostas ou nos canais de drenagem;

3. Acesso a saneamento básico e saúde: como foi apresentado, determinadas áreas não têm acesso a água tratada ou esgotamento sanitário, elevando e muito o risco doenças por veiculação hídrica.

4. Criminalidade: os moradores estão sujeitos a facções criminosas, mesmo não tendo nenhuma participação.

\section{Considerações finais}

A forma como se deu a ocupação das encostas do Rio de Janeiro, sem um planejamento que delimitasse as áreas seguras para a construção das residências, culminou no atual cenário de risco das comunidades cariocas. As vertentes são o caminho natural das águas das chuvas, a remoção da vegetação dificulta a infiltração e a declividade acentuada aumenta a força de arraste da água que por ali escoa. O baixo padrão construtivo das casas e a falta de obras de contenção adequadas, agravada pelas condições naturais do relevo, contribuem para que movimentos de massas e enxurradas culminem em desastres.

O cenário de risco existente na comunidade João Paulo II reflete as políticas de urbanização adotadas no Rio de Janeiro nas últimas décadas, não se tratando de um caso isolado, pelo contrário, se tornou um padrão visível nas encostas. É um reflexo de uma política de urbanização que priorizou uma classe econômica com maior poder aquisitivo e afastou a classe operária das áreas planas, consideradas "nobres" e alvo da especulação imobiliária. O êxodo rural ocorrido no Nordeste durante a "Revolução Verde" e a promessa de uma vida próspera no Sudeste, que estava se industrializando, trouxe um contingente de pessoas maior que a cidade comportava naquele momento. Aumentou a mão de obra de baixo custo, porém, aumentou também a demanda por moradia e saneamento básico. Os operários precisavam morar próximos aos seus trabalhos e não podiam pagar o valor dos aluguéis no "asfalto", a alternativa viável foi ocupar as encostas próximas. Esse processo continuou nas décadas seguintes e as poucas tentativas de urbanizar as favelas, a partir da década de 1990, não foram suficientes para mitigar o risco de desastres.

O Poder Público através dos programas realizados na comunidade João Paulo II, mesmo que de forma prolongada, demonstrou esforços em oferecer um pouco mais de dignidade e segurança aos moradores. No entanto, muito ainda precisa ser trabalhado e para isso é fundamental que os moradores e as lideranças comunitárias sejam consultados e ouvidos. Ao exercer seu papel de gestor, os órgãos públicos devem atuar de diferentes formas: utilizando-se da alocação de investimentos públicos de forma eficiente, promovendo políticas públicas para toda a população, elaborando o planejamento urbano, aplicando a legislação urbanística e atuando através dos programas habitacionais, bem como incentivando a melhoria na infraestrutura urbana. O problema é que, na maioria das 
vezes, os programas são feitos sem a participação dos moradores e as soluções que a princípio pareciam eficazes, se tornam inviáveis por questões intrínsecas à organização social de comunidades carentes. Não é possível conhecer tais nuances sem vivenciar a realidade daquelas pessoas e sua organização socioespacial. Desta forma, tais soluções se transformam em novos problemas, pois o erro das soluções simplistas para resolução de problemas complexos está no fato de não levarem em consideração todas as variáveis envolvidas, como o custo do deslocamento dos moradores para o trabalho ou as relações sociais complexas em uma forma de organização tão peculiar.

Precisamos melhorar a forma de trabalhar a educação em qualquer programa de governo implantado em favelas. Não adianta prover recursos, como canaletas para escoamento das águas pluviais, se a população não compreender a importância das mesmas e as utilizarem como lixeira. Entendemos que os recursos financeiros que são destinados para a solução de problemas cotidianos nas favelas são limitados e, por isto mesmo, devem ser adequadamente aplicados.

A participação da própria comunidade no processo deve ser priorizada para dar legitimidade às ações, garantir a eficácia e evitar o estabelecimento de novos conflitos. Alguns moradores mostraram interesse e preocupação em desenvolver e participar de programas de cunho ambiental e educativo, todavia, não foi dado continuidade aos programas pelo governo. O projeto de coleta e reciclagem de resíduos sólidos, de iniciativa dos próprios moradores, não pode continuar por falta de interesse em parceria para manutenção das atividades. Este projeto além de desenvolver uma conscientização conjunta, retiraria toneladas de materiais recicláveis da natureza, evitaria a poluição, acabaria com o problema de entupimento das caneletas e ainda geraria renda para muitos moradores.

Há de observar ainda, que apesar do reconhecimento pelas lideranças comunitárias locais, o Programa Morar Carioca implementado pela Prefeitura da Cidade do Rio de Janeiro foi totalmente descaracterizado no que diz respeito à proposta original desse programa. Quando lançado em 2010, previa não só uma expressiva participação comunitária - no que se refere à concepção e implantação dos projetos urbanísticos -, como também a inserção de soluções ambientalmente sustentáveis e a assessoria técnica para a promoção de melhorias nas moradias das comunidades atendidas.

As ações da Defesa Civil são bem quistas pelos moradores e voltadas à promover simulados educativos, monitorar as áreas de risco geológico em chuvas intensas, a fim de emitir alertas e atender a população quando solicitados. Entendemos que falta recursos a este órgão para ir além das ações até o momento desenvolvidas, pois além da Proteção e Defesa Civil não ser uma área prioritária para investimentos no país, as comunidades carentes também não estão entre as prioridades da gestão pública.

É de suma importância que sejam mantidos os serviços básicos, como distribuição de água tratada, energia elétrica, coleta de esgoto e resíduos sólidos, captação de águas pluviais, educação e serviços de saúde para a comunidade. Estes serviços, que para muitos parecem comuns, muitas vezes inexistem nas favelas. Os moradores precisam se sentir valorizados enquanto cidadãos e ouvidos pelo Poder Público. A participação nas decisões que os afetam diretamente, fortalece o reconhecimento dos mesmos como agentes fundamentais na construção de uma comunidade segura e promove uma melhoria na qualidade de vida, além de auxiliar o Poder Público a adotar medidas eficientes para a resolução dos múltiplos problemas característicos das favelas cariocas. O planejamento dessas áreas e as ações preventivas devem ser priorizadas para que o risco de desastres seja minimizado, na medida do possível.

\section{Referências}


BARROS, R.P.; COUTINHO, M.A.; RIBEIRO, M.J. Histórias de favelas da Grande Tijuca contadas por quem faz parte delas. Agenda Social Rio. Projeto Construtores de Memória. Rio de Janeiro: IBASE, 2006.

BELCHIOR, A. O retorno do gari comunitário nas comunidades do Rio de Janeiro. Portal da Vila Kennedy. 2016. Disponível em: <http://www.vilakennedy.com/fala/2015/022.htm>. Acessado em: 27 de maio de 2017.

BRASIL. CONSTITUIÇÃO DA REPÚBLICA FEDERATIVA DO BRASIL. Brasília : Governo Federal, 1988.

BRASIL. Classificação Brasileira de Desastres - COBRADE. Ministério da Integração: Governo Federal. Disponível em: http://www.mdr.gov.br/defesa-civil/centro-nacional-de-gerenciamentode-riscos-e-desastres-cenad/entenda-os-desastres

BRASIL. Urbanização Favelas: Nova Divinéia, Borda do Mato, Parque JK, João Paulo II, Bairro do Grajaú - Rio de Janeiro - RJ. PAC. Ministério do Planejamento, 31 de dezembro de 2016. Disponível em: http://www.pac.gov.br/obra/26816. Acessado em: 27 de maio de 2017.

CAVALLIERI, F. e LOPES, G.P. Favelas cariocas: comparação das áreas ocupadas 1999/2004. COLEÇÃO ESTUDOS CARIOCAS. Rio de Janeiro : Instituto Pereira Passos, 2006.

CAVALLIERI, F.; VIAL, A. O efeito da presença governamental sobre a expansão horizontal das favelas do Rio de Janeiro: os Pouso's e o Programa Favela-Bairro. COLEÇÃO ESTUDOS CARIOCAS. Rio de Janeiro : Instituto Pereira Passos, 2009.

CENAD. 2012. Anuário Brasileiro de Desastres Naturais. Brasília : Brasil, 2012.

CORTEZ, A.T.C.; FILHO, A.R. A problemática sócioambiental da ocupação urbana em áreas de risco de deslizamento da "Suiça Brasileira". Revista Brasileira de Geografia Física. 2010. Disponível em: <http://www.revista.ufpe.br/rbgfe/index.php/revista/article/view/76/76>. Acessado em: 27 de maio de 2017.

DELECAVE, J.; LEITÃO, G. O programa Morar Carioca: novos rumos na urbanização das favelas cariocas: Práticas recentes de intervenções contemporâneas em cidades da América Latina. São Paulo : FAUUSP, 2014, p. 131-147.

EIRD/ONU. 2004. La Gestion del Riesgo de Desastres Hoy - Glossario. Naciones Unidas Estrategia internacional para la Reducción de Desastres. 2004. Disponível em <https://eird.org/gestion-del-riesgo/glosario.pdf>. Acessado em 18 de 05 de 2019.

FERNANDES, R.B.; TEIXEIRA, M.A. Sentidos da participação social em favelas "pacificadas": notas sobre a experiência do Programa Territórios da Paz. Revista Pensata, v.5, n.1. São Paulo: UNIFESP, 2016, p. 128-148.

FRANCA, N.; LEITE, M.P.; SANTOS, A.M. Quando memória e história se entrelaçam: a trama dos espaços na Grande Tijuca. Rio de Janeiro : IBASE, 2003.

GEORIO. SIURB - Sistema Municipal de Informações Urbanas. Portal GEORIO. Prefeitura do Rio de Janeiro, 2016. Disponível em: <http://portalgeo.rio.rj.gov.br/>. Acessado em: 27 de maio de 2017.

GOVERNO DO RIO DE JANEIRO. Plano de história e memórias das favelas. Governo do Estado do Rio de Janeiro. 29 de janeiro de 2014. Disponível em: <http://www.rj.gov.br/web/seasdh/exibeconteudo?article-id=1940883>. Acessado em: 27 de maio de 2017. 
IBGE. Censo 2010: Aglomerados Subnormais - Informações Territoriais. Instituto Brasileiro de Geografia e Estatística. 2010.2 Disponível em: <http://www.ibge.gov.br/home/presidencia/noticias/imprensa/ppts/00000015164811202013480 105748802.pdf>. Acessado em: 27 de maio de 2017.

2010a. Censo 2010: Aglomerados subnormais: Primeiros resultados. Instituto Brasileiro de Geografia e Estatística. IBGE, 2010a. Disponível em: <http://www.ibge.gov.br/home/estatistica/populacao/censo2010/aglomerados_subnormais/aglo merados_subnormais_tab_brasil_zip.shtm>. Acessado em: 27 de maio de 2017.

INSITE ARQUITETOS. Insite Arquitetos. 2001. Disponível em: <http://www.insitearquitetos.com.br/>. Acessado em: 27 de maio de 2017.

LEITÃO, G. Dos barracos de madeira aos prédios de quitinetes:Uma análise do processo de produção da moradia na favela da Rocinha ao longo de cinqüienta anos. Niterói: EDUFF, 2006.

LEITE, M.P. Grajaú, memória e história: fronteiras fluidas e passagens. Cadernos Metrópole. São Paulo, v.5. PUCSP, 2001. p. 91-125.

PINHEIRO, A.I.F. Políticas públicas urbanas na Prefeitura do Rio de Janeiro. Coleção Estudos Cariocas. Rio de Janeiro : Instituto Pereira Passos, 2008.

ROMAR, J. Guardiões dos Rios beneficiam 24 comunidades. Prefeitura do Rio de Janeiro. 01 de abril de 2013. Disponivel em : <http://www.rio.rj.gov.br/web/guest/exibeconteudo?id=4113492>. Acessado em: 27 de maio de 2017.

SCHLEE, M.B. Ocupação de encostas urbanas: algumas considerações sobre resiliência e sustentabilidade. Caderno Metrópole, v.15, n.29. São Paulo : PUCSP, 2013, p. 241-264. 